\title{
Spatial and seasonal distribution of Lutzomyia longipalpis in Dracena, a city in the western region of the State of São Paulo, Brazil, that is endemic with visceral leishmaniasis
}

\author{
Marcia Moreira Holcman[1], Susy Mary Perpetuo Sampaio ${ }^{[2],}$ \\ Osias Rangel[ ${ }^{[3]}$ and Claudio Casanova ${ }^{[4]}$
}

[1]. Diretoria de Combate a Vetores, Superintendência de Controle de Endemias, Secretaria de Estado da Saúde de São Paulo, São Paulo, SP. [2]. Serviço Regional de Presidente Prudente, Superintendência de Controle de Endemias, Secretaria de Estado da Saúde de São Paulo, Presidente Prudente, SP. [3]. Serviço Regional de Campinas, Superintendência de Controle de Endemias, Secretaria de Estado da Saúde de São Paulo, Campinas, SP. [4]. Laboratório de Mogi-Guaçu, Superintendência de Controle de Endemias, Secretaria de Estado da Saúde de São Paulo, Mogi Guaçu, SP.

\begin{abstract}
Introduction: Vector seasonality knowledge is important for monitoring and controlling of vector-borne diseases. Lutzomyia longipalpis (Lu. longipalpis) is the main vector of Leishmania (Leishmania) infantum Nicolle, 1908, which is the causative agent of visceral leishmaniasis in the Americas. Methods: Lu. longipalpis was monitored for 3 consecutive nights each month using light traps from the Centers for Disease Control in the peridomiciles and intradomiciles of 18 residences from January 2005 to December 2012 in the urban area of Dracena, a medium-sized city located in the western region of São Paulo, Brazil. Results: A total of 54,820 Lu. longipalpis specimens were collected, and the proportion of positive samples was significantly higher in the peridomiciles than in the intradomiciles $(p<0.05)$ in all 8 years of the study, except for 2005 . The vector was present in all study years in the 9 sub-regions of the city, and the male/female ratio ranged from 3.19 to 4.26 . The greatest vector abundance occurred in the first semester and peaked in March, confirming its seasonality. Conclusions: The maintenance of this high abundance over an 8-year surveillance period demonstrates the vector adaptation to the urban conditions of the city. These characteristics present a major challenge for preventing human and canine contact with the vector and, consequently, controlling the spread of disease.
\end{abstract}

Keywords: Lutzomyia longipalpis. Visceral leishmaniasis. Time series. Dracena. São Paulo.

\section{INTRODUCTION}

It is essential to obtaining information about insect abundance to study the dynamics of vector-borne transmitted diseases and to plan the appropriate measures to control such diseases. Lutzomyia longipalpis (Lutz \& Neiva 1912) is the main vector of Leishmania (Leishmania) infantum (Nicolle, 1908), which is the causative agent of visceral leishmaniasis (VL) in the Americas, a disease that has spread throughout Brazil over the last 20 years. Rapid urbanization and recent environmental modifications and the adaptation of Lutzomyia longipalpis (Lu. longipalpis) to urban areas are thought to be the main factors associated with the increased number of reported VL cases in Brazil ${ }^{1-4}$.

In the State of São Paulo, which is located in the southeastern region of Brazil, 2,146 VL cases were reported between 2001 and $2012^{5}$. Therefore, the number of municipalities affected by human cases of the disease increased from 4 to 75 within

\footnotetext{
Address to: Dra Marcia Moreira Holcman. DCV/SCE/Secretaria de Estado da Saúde. Rua Paula Souza 166, 01027-000 São Paulo, SP, Brasil.

Phone: 5511 3311-1108

e-mail: marciaholcman@gmail.com

Received 17 September 2013

Accepted 28 November 2013
}

this period. Additionally, the presence of Lu. longipalpis has been reported in 148 of the 645 municipalities in the State of São Paulo ${ }^{6}$.

The recommended disease control measures include diagnosing and treating human cases, monitoring and controlling seroreactive dogs, and chemically controlling the vectors ${ }^{7}$. Vector seasonality is an important factor, as it can improve the effectiveness of the control measures by determining the best time to implement chemical and environmental procedures to reduce the abundance of the vector. However, a wide range of annual climatic conditions, primarily temperature and rainfall, may hinder the identification of a fluctuation pattern and the discovery of possible associations between these factors during a short follow-up period. Although the temporal and spatial dynamics of $\mathrm{Lu}$. longipalpis have been described in municipalities located in the States of Minas Gerais, Mato Grosso do Sul, Sergipe, Rio Grande do Norte, and São Paulo ${ }^{8-13}$, there is still a need to analyze its temporal and spatial dynamics for longer time periods. This paper aimed to describe the epidemiological situation and the abundance of $L u$. longipalpis in intradomicile and peridomicile habitats and to determine their associations with the weather variables and in human and canine cases during 8 years of surveillance in the urban area of Dracena, a municipality situated in the western region of the State of São Paulo that is endemic with visceral leishmaniasis. 


\section{METHODS}

\section{Study area}

This observational ecological study occurred in the municipality of Dracena, which is located in the western region of São Paulo and has 43,258 inhabitants ${ }^{14}$ in an area of $488 \mathrm{~km}^{2}$. The city is geographically situated at the coordinates $21^{\circ} 28^{\prime} 57^{\prime \prime} \mathrm{S}$ and $51^{\circ} 31^{\prime} 58^{\prime \prime} \mathrm{W}$ at an altitude of 421 meters. Based on the Köppen climate classification, this region is classified as $\mathrm{Cwa}$, with dry winters. It has an average temperature of $24.52^{\circ} \mathrm{C}$, ranging from a maximum of $36.52^{\circ} \mathrm{C}$ to a minimum of $12.75^{\circ} \mathrm{C}$ and annual precipitation of $1,513 \mathrm{~mm}$ over the last 3 years. Dracena is one of the municipalities of the State of São Paulo that has been classified as a high priority by the Brazilian Ministry of Health ${ }^{15}$.

\section{Visceral leishmaniasis human and canine cases}

The first canine and human cases were reported in $2005^{16}$. The VL cases were obtained from the Epidemiologic Center of São Paulo, and the canine positivity rate was gathered from the local zoonosis center for the period between 2006 and 2012. The percent positivity for canine VL was obtained by dividing the number of seroreactive dogs by the number of tested dogs and then multiplying by 100 .

\section{Sandfly collection}

Dracena was divided into 2 areas: the first area with 4 subregions and the second area with 5 sub-regions. This partition followed the divisions employed by the Dengue Control Program ${ }^{7}$. Lu. longipalpis was initially detected in sub-region 3 of area 2 in March 2003, and all 9 sub-regions were infested with the vector by March 2004. The sandfly collections were conducted for 3 consecutive nights monthly from January 2005 to December 2012 using light traps (LTs) from the Centers for Disease Control and Prevention $(\mathrm{CDC})^{17}$. To cover the entire territory of each of the 9 sub-regions, 2 houses were selected based on the appropriate conditions for the presence of sandflies, including shaded and humid backyards and the presence of domestic animals. From $6 \mathrm{pm}$ to $8 \mathrm{am}, 2$ traps were placed at every house: 1 outside the house (peridomicile), which was associated with the domestic animal (i.e., dogs, chickens, or birds) shelters, and the other trap was placed inside the house (intradomicile). Overall, the collection effort involved 18 urban houses and resulted in 36 CDC LTs per night and a total of 108 traps per month; the selected houses changed every 2 years. All analyses were conducted using the sum of the sandflies collected per month.

The collected sandflies were processed according to Forattini and were identified using the taxonomic key of Galati ${ }^{18}$.

The 15, 30 and 45-day accumulated rainfall data were obtained from the Coordenadoria de Assistência Técnica Integrada ${ }^{19}$ for the Dracena region.

\section{Data analysis}

The chi-squared test was used to compare the proportions. The trend and seasonality of the number of Lu. longipalpis specimens collected each month were analyzed from January
2005 to December 2012. The trend was visually analyzed by plotting the aggregated data by year, and the Cox-Stuart test was used to confirm statistical significance. A box plot of the monthly data was plotted to analyze the seasonal behavior of the vector. To evaluate the relationship between the accumulated rain in the 15,30 , and 45 days prior to the entomological collections and the number of $L u$. longipalpis specimens collected monthly, a scatter plot was built, and Spearman's rank correlation (rho) was calculated to measure the linear relationships between these factors. Similarly, Spearman's rho correlation was calculated using the accumulated information of the period in the 9 subregions to measure the linear relationships between the human incidence rate and the mean canine positivity, the number of specimens collected and the human incidence rate, and the number of specimens collected and the mean canine positivity in that period. A significance level of 5\% was used in all tests. All data were registered in the siszoo, a computerized system used to monitor the information from the Control Program of Visceral Leishmaniasis in the State of São Paulo ${ }^{20}$. Statistical analyses were performed using the R software(version 3.0.1; R Foundation for Statistical Computing, website:http://www.Rproject.org/;Vienna, Austria).

\section{RESULTS}

During the 96 months of the study (January 2005 to December 2012), a total of 54,983 sandflies were collected. Lu. longipalpis represented $99.7 \%$ of the total sandflies collected (54,820 specimens), and the remaining 163 (0.3\%) specimens belonged to other species, including 61 Nyssomyia neivai (Pinto, 1926), 21 Nyssomyia whitmani (Antunes \& Coutinho, 1939), 59 Evandromyia cortelezzii (Brèthes, 1923), and 22 Brumptomyia sp. This paper describes only the results related to the Lu. longipalpis specimens.

From 2006 to 2012, 119 VL human cases were reported in Dracena. Most (68.1\%) of the human cases were reported in 2006 and 2007, with each sub-region registering at least 1 case. The mean percentage of canine positivity ranged from $16.4 \%$ to $34.4 \%$ in the 9 sub-regions during this period, and there were no correlations between the mean canine positivity rate and the human incidence rate during this period $(\mathrm{rho}=0.21$, $\mathrm{p}$-value $=0.58$ ) (Figure 1C). Additionally, the number of $\mathrm{Lu}$. longipalpis specimens collected in each sub-region varied every year, demonstrating that the vector was present in all regions but with no marked predominance in any one region. The correlation between the number of Lutzomyia longipalpis specimens collected and the human incidence rate was 0.20 (p-value $=0.61)$ (Figure 1A), and the correlation between the number of $L u$. longipalpis specimens and the canine positivity rate was 0.08 (p-value $=0.83$ ) (Table 1 and Figure 1B).

From January 2005 to December 2012, 10,339 catches were performed, with $5,171(50 \%)$ in the peridomicile and $5,168(50 \%)$ in the intradomicile. Lu. longipalpis was detected in $3,834(37.1 \%)$ of these surveys, resulting in $2,380(46 \%)$ positive traps in the peridomicile and 1,454 (28.1\%) positive traps in the intradomicile. The proportion of positive samples 
(A)

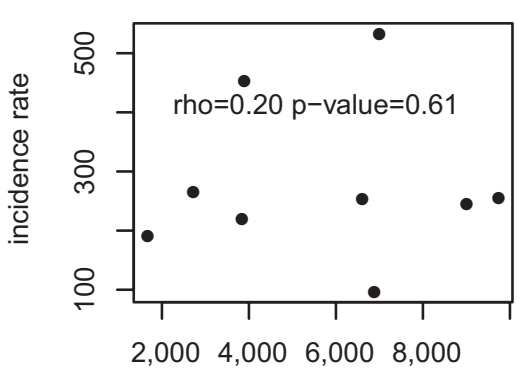

$\mathrm{n}^{\circ}$ specimens
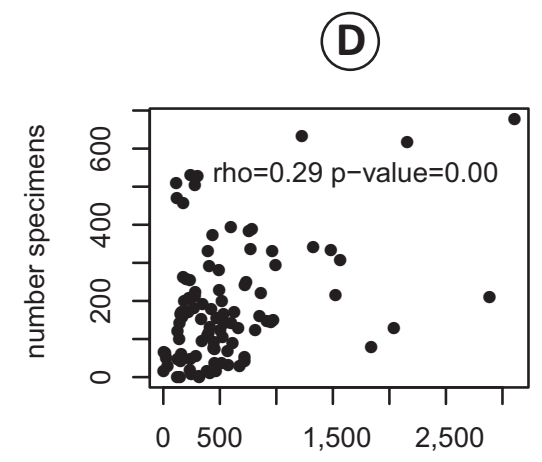

$\mathrm{mm}$ of rain 45 days before collection
(B)

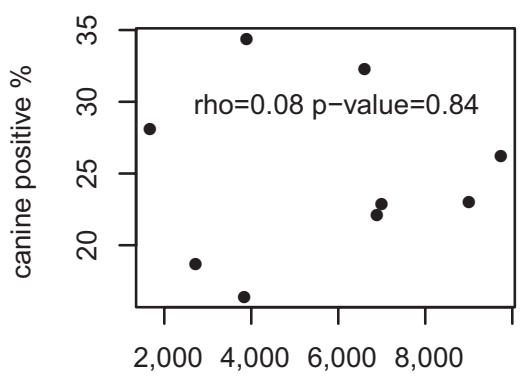

$\mathrm{n}^{\circ}$ specimens
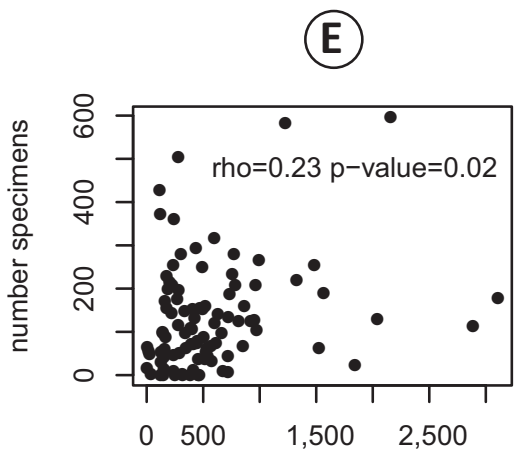

$\mathrm{mm}$ of rain 30 days before collection
(C)

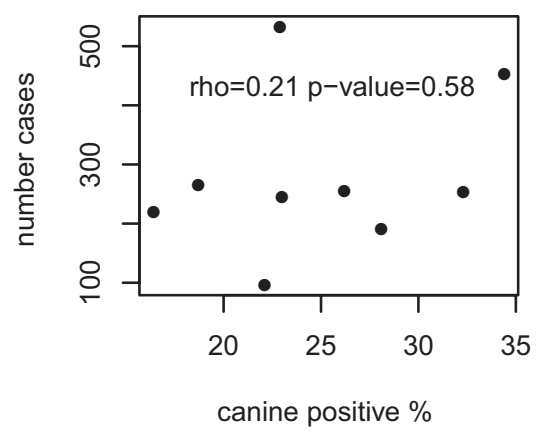

(F)

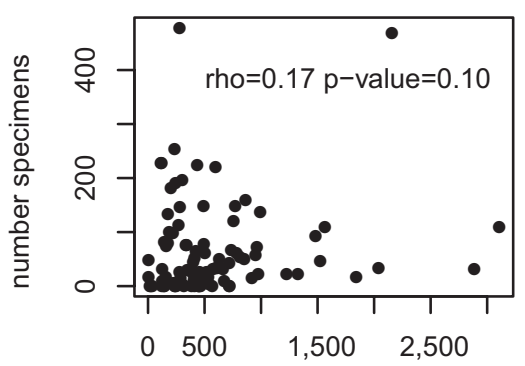

$\mathrm{mm}$ of rain 15 days before collection

FIGURE 1 - A: A scatter plot of the incidence rate and number of specimens collected. B: A scatter plot of the mean canine positivity rates and the number of specimens collected. C: A scatter plot of the incidence and mean canine positivity rates. D: A scatter plot of rain accumulation for the 45 days prior to collection and the number of specimens collected. E: A scatter plot of rain accumulation for the 30 days prior to collection and the number of specimens collected. F: A scatter plot of rain accumulation for the 45 days prior to collection and the number of specimens collected. In the Graphs A, B and C the number of specimens collected in Dracena, State of São Paulo, from 2006 to 2012 and in the Graphs D, E and F the number of specimens collected in Dracena, State of São Paulo, from 2005 to 2012.

was significantly higher in the peridomiciles than in the intradomiciles ( $\mathrm{p}$-value $<0.05$ ) for all 8 years of the study, except for 2005, which showed similar positivity for both locations ( $\mathrm{p}$-value $=0.82$ ). The positivity of the captures was also compared between the first and the second semesters of the year, showing a greater number of positive collections in the first semester than in the second semester ( $p$-value $<0.05$ ). Two exceptions occurred during this period: in 2007, the positivity was similar between the first and second semesters ( $p$-value $=0.23$ ), and in 2009, the second semester presented a greater proportion of positive captures ( $p$-value $=0.01$ ) than the first semester.

The greatest number of sandflies was captured in the peridomiciles, with 48,606 specimens collected $(88.7 \%$ of the total), which included 38,304 (78.8\%) males and 10,302 $(21.2 \%)$ females. Of the 6,214 specimens collected in the intradomicile, 4,544 (73.1\%) were males, and 1,670 (26.9\%) were females. In general, the proportion of males to females varied significantly ( $p$-value $<0.01$ ) according to the collection location (i.e., the intradomicile and peridomicile). Overall, the $\mathrm{M} / \mathrm{F}$ ratio by year ranged from 3.19 to 4.26 , and the correlation was 0.97 during this period, as measured between the males and females (Table 2).
The greatest abundance occurred in the years $2009(12,749$ specimens) and 2008 (10,223 specimens). The vector was collected in all months during the study period, with a peak of 3,106 specimens in March 2009. The lowest number of specimens (4 specimens) was collected in Augus2011 (Figure 2A). The aggregated data showed a rise in the number of specimens collected from 2007 to 2009 , followed by a decrease in 2010, and the Cox-Stuart test indicated an absence of a trend for the entire period ( $\mathrm{T}=27$, p-value $>0.05$ ) (Figure 2B). The box plot graph shows that the number of specimens per month exhibited an elevated dispersion, mainly in the beginning of the year. The greatest abundance of the vector occurred in the months of February, March, and April, with median numbers of 684, 805, and 935 specimens, respectively. This finding confirmed the seasonality of this vector (Figure 2C).

The highest correlation between the number of specimens collected and the accumulated rainfall was obtained in the 45 days prior to the collection date ( $r$ o $=0.29$, $\mathrm{p}$-value $=0.00$ ). Between the number of specimens and the accumulated rainfall in the 30 days prior to collection, the rho was 0.23 ( $\mathrm{p}$-value $=0.02$ ), and the rho was 0.17 between the number of specimens and the accumulated rainfall 15 days prior to the collection date (p-value $=0.10)($ Figures 1D, 1E, 1F, and Figure 3). 


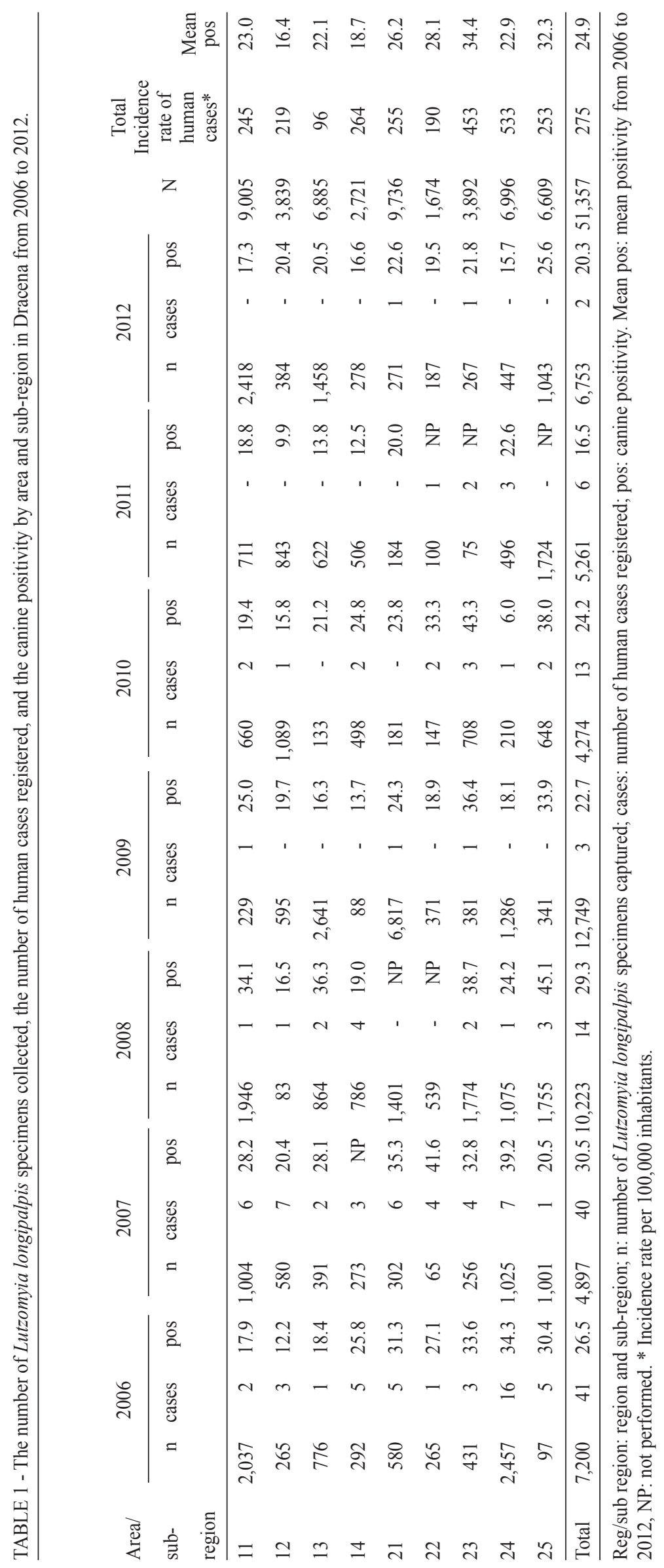


TABLE 2 - The sex and number of Lutzomyia longipalpis specimens in each Dracena location from 2005 to 2012.

\begin{tabular}{|c|c|c|c|c|c|c|c|c|c|c|c|c|c|}
\hline \multirow[b]{2}{*}{ Year } & \multicolumn{4}{|c|}{ Peridomicile } & \multicolumn{4}{|c|}{ Intradomicile } & \multicolumn{4}{|c|}{ Total } & \multirow[b]{2}{*}{ Peri/Intra } \\
\hline & males & females & total & $\mathrm{M} / \mathrm{F}$ & males & females & total & $\mathrm{M} / \mathrm{F}$ & males & females & total & $\mathrm{M} / \mathrm{F}$ & \\
\hline 2005 & 1,609 & 477 & 2,086 & 3.4 & 1,034 & 343 & 1,377 & 3.0 & 2,643 & 820 & 3,463 & 3.2 & 1.5 \\
\hline 2006 & 4,387 & 953 & 5,340 & 4.6 & 1,443 & 417 & 1,860 & 3.5 & 5,830 & 1,370 & 7,200 & 4.3 & 2.9 \\
\hline 2007 & 3,471 & 1,048 & 4,519 & 3.3 & 256 & 122 & 378 & 2.1 & 3,727 & 1,170 & 4,897 & 3.2 & 12.0 \\
\hline 2010 & 3,015 & 919 & 3,934 & 3.3 & 238 & 102 & 340 & 2.3 & 3,253 & 1,021 & 4,274 & 3.2 & 11.6 \\
\hline 2011 & 3,707 & 1,078 & 4,785 & 3.4 & 305 & 171 & 476 & 1.8 & 4,012 & 1,249 & 5,261 & 3.2 & 10.1 \\
\hline 2012 & 4,707 & 1,156 & 5,863 & 4.1 & 639 & 251 & 890 & 2.5 & 5,346 & 1,407 & 6,753 & 3.8 & 6.6 \\
\hline
\end{tabular}

$\mathrm{M} / \mathrm{F}:$ male/female ratio

(A)

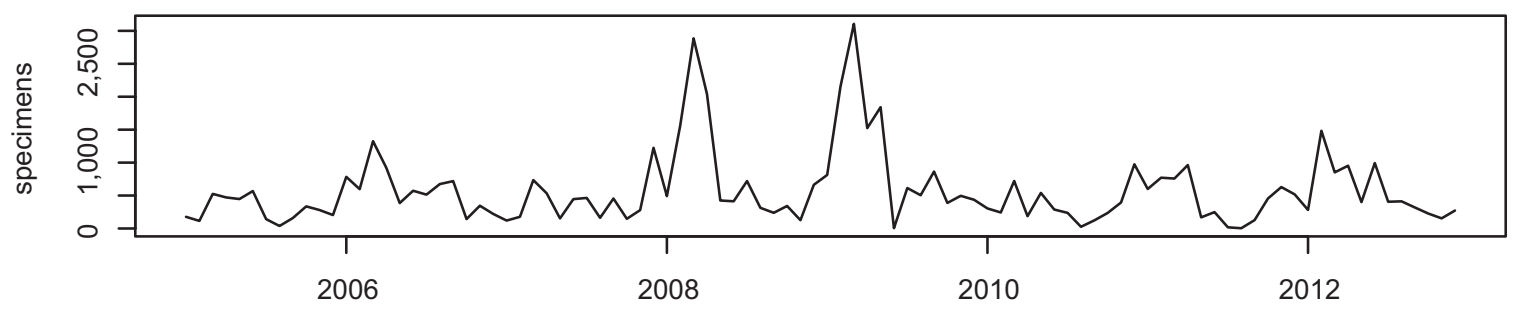

(B)

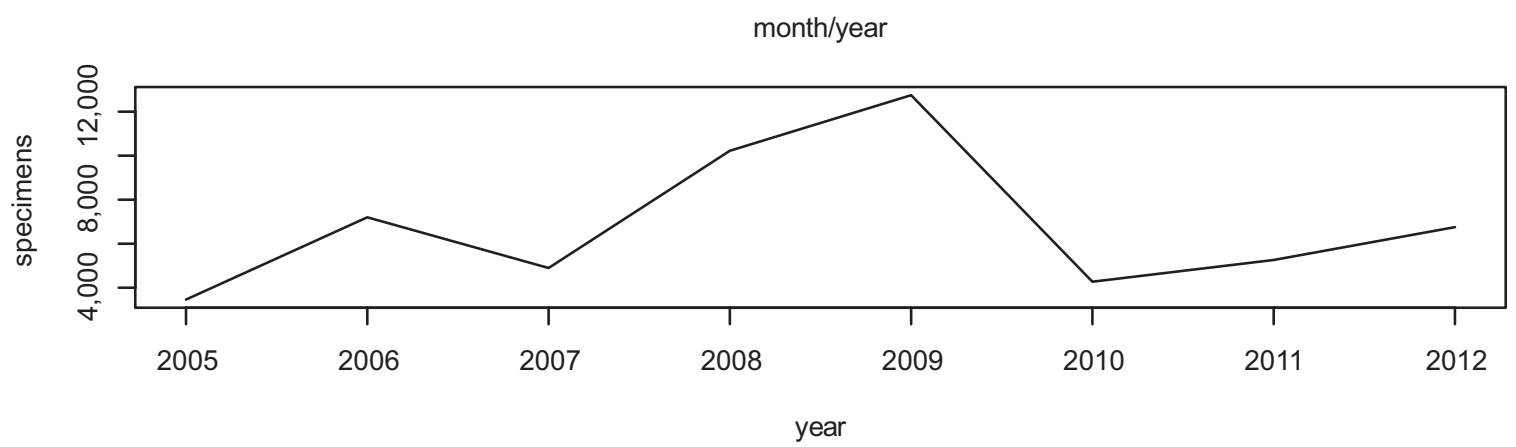

(C)

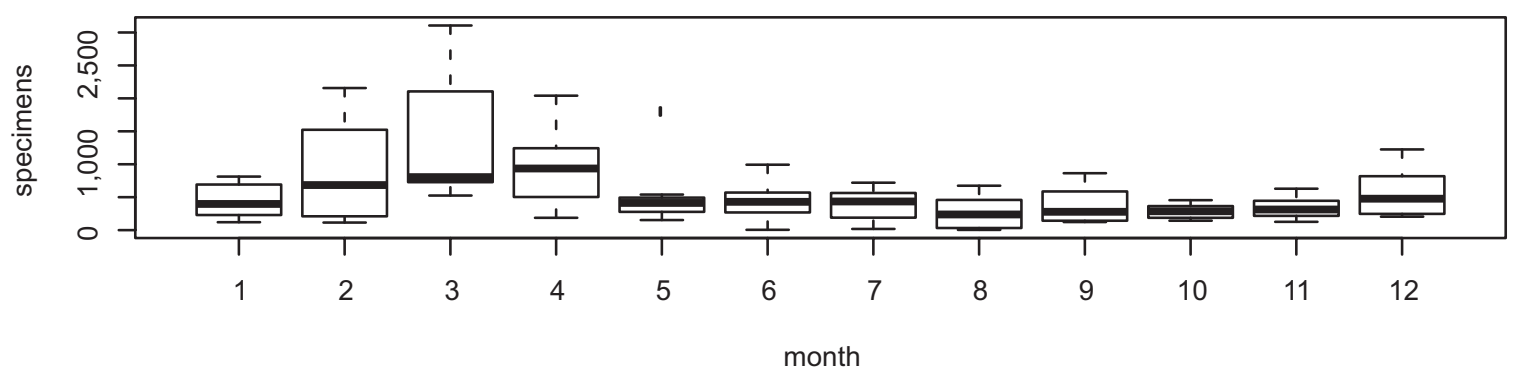

FIGURE 2 - A: The number of Lutzomyia longipalpis specimens collected per month in Dracena, State of São Paulo, Brazil. B: The aggregated number of Lutzomyia longipalpis specimens collected per year from 2005 to 2012 in Dracena, State of São Paulo, Brazil. C: A box-plot of the number of Lutzomyia longipalpis specimens collected each month from 2005 to 2012 in Dracena, State of São Paulo, Brazil. 

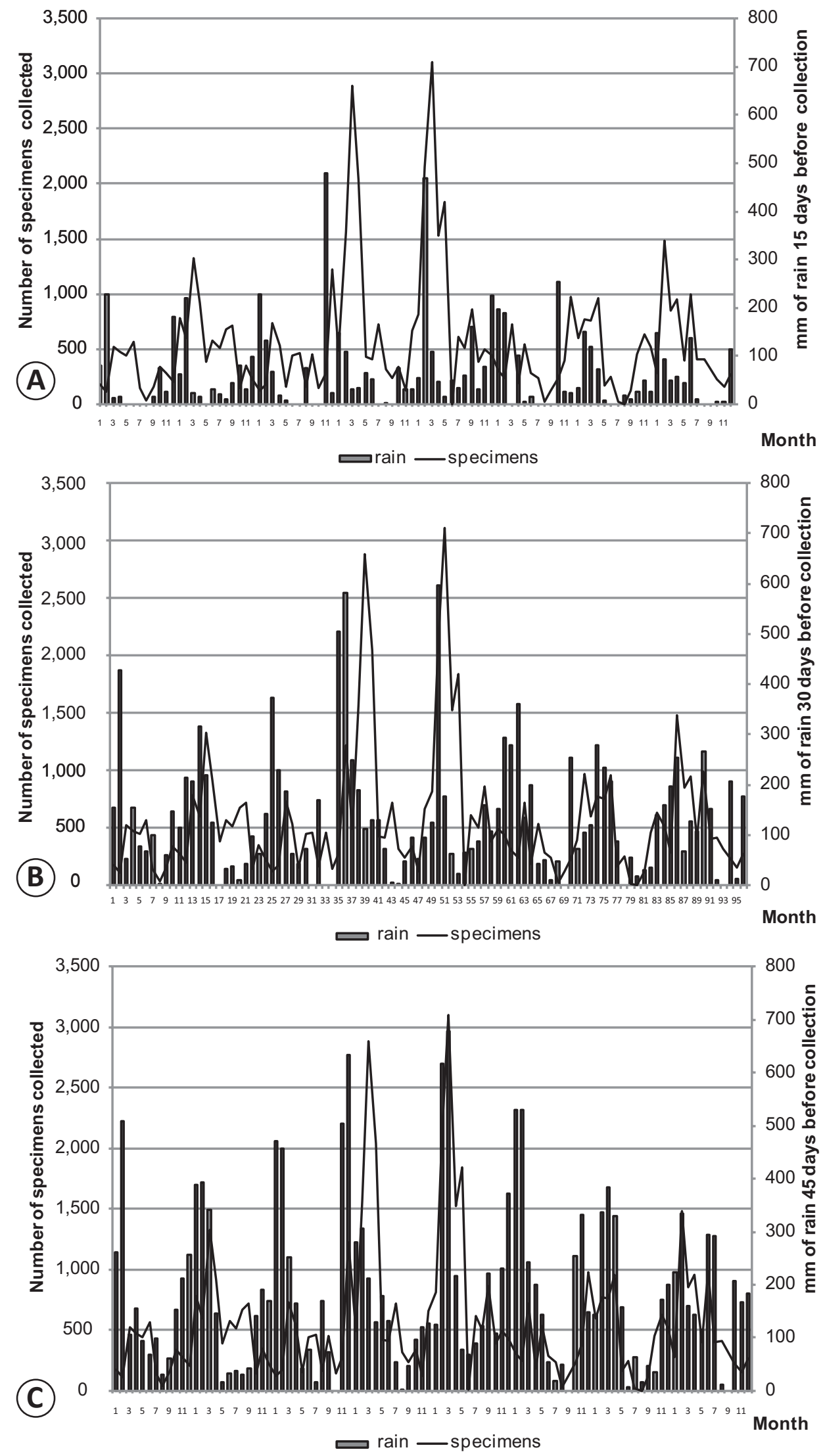

FIGURE 3 - A: The number of Lutzomyia longipalpis specimens collected each month and the accumulated rain for the 15 days prior to collection from 2005 to 2012 in Dracena, State of São Paulo, Brazil. B: The number of Lutzomyia longipalpis specimens collected each month and the accumulated rain for 30 days prior to collection from 2005 to 2012 in Dracena, State of São Paulo, Brazil. C: The number of Lutzomyia longipalpis specimens collected each month and the accumulated rain for 45 days prior to collection from 2005 to 2012 in Dracena, State of São Paulo, Brazil. 


\section{DISCUSSION}

The vector was collected in all months and in all 9 subregions of the city during the 8 years of the study, indicating its adaptation to the urban areas of Dracena. Combined with the canine positivity, these results demonstrate that despite the decreased number of reported human cases, the conditions for disease dissemination in humans and dogs continued during this period, as the high abundance of the vector in the intradomicile and peridomicile habitats facilitated contact between the humans and the vector inside the homes and between the domestic animals and the vector outside the residences.

Lutzomyia longipalpis presented the highest abundance of the sandfly species collected in Dracena, with predominance in the peridomicile; a greater proportion of males was collected. These results were consistent with the results of other studies using LTs in urban areas of endemic cities in other Brazilian states $^{8-10,21-27}$. The greater abundance of the vectors in the peridomestic habitats may be associated with the attraction exerted by the animals that were present in this environment, as the LTs were specifically positioned near the animal shelters that provide their food sources. Similarly, the bias in the proportion of Lu. longipalpis males may be associated with the lek-like aggregations that occur on the host animals, which attract the females to mate and obtain their blood meal source ${ }^{28,29}$. However, the vector was also found in the intradomicile, increasing the risk of human contact. Considering that $\mathrm{Lu}$. longipalpis boasts an eclectic feeding habit, the presence of females in the intradomicile increases the risk of acquiring LV.

The vector was detected in all months throughout the year, with seasonal peaks occurring from January to May and coinciding with the warmest and rainiest months of the year. This finding corroborates other studies performed in several cities located in the southeastern and central regions of Brazil, such as Janauba $^{21}$, Belo Horizonte ${ }^{27}$, Montes Claros ${ }^{30}$, Campo Grande ${ }^{9}$, and Barra do Garças ${ }^{26}$. Moreover, in northeastern Brazil, where temperatures vary little throughout the year, the greater abundance of the vector occurs during the rainy season, which ranges from June to August ${ }^{10,11,31}$. In other studies performed in the cities of Porteirinha ${ }^{23}$ and Montes Claros ${ }^{25}$, both of which are located in Minas Gerais in southeastern Brazil, the rainfall and the temperature were considered to be predictors of vector abundance. The combined effects of rainfall, air temperature, and evapotranspiration, which determine the soil water balance, most likely influence the quality of the breeding site habitats and, consequently, determine the fluctuations in the adult sandfly population $^{13,32-34}$. In our study, the $<0.50$ correlation index between the number of Lu. longipalpis specimens collected and the previous accumulated rainfall indicated that this variable was only poorly associated with vector abundance, and other variables that affect microhabitats, such as the presence of animals and the availability of organic matter, might also be used as factors in a predictive model.

The role of canines as disease reservoirs has been well established ${ }^{35,36}$. In our study, the observed canine infection positivity rate of approximately $24 \%$ was high compared to other endemic cities and did not correlate with the number of human cases or the abundance of Lu. longipalpis, which aligned with other studies ${ }^{20,22,37}$. However, these results should be considered with caution, as these surveys do not always represent the true positivity in the canine population because of the difficulties associated with human and canine diagnoses ${ }^{4}$. There are additional issues to consider, including the possible number of underreported human cases ${ }^{38}$ and issues related to the disease transmission, such as environmental features and socio-demographic conditions, which are difficult to measure ${ }^{2,3}$.

Dracena has some transitional urban/rural areas with ample backyards. Some houses have chicken breeding sites, and additional animals and other environmental characteristics, such as shaded areas with large trees, are also present. These conditions appear to be suitable breeding sites in the peridomicile habitat of this municipality, given that that $L u$. longipalpis was present in only 1 of the 9 sub-regions in March 2003 and spread throughout the entire city within a 1-year period, reaching a high abundance in all 9 sub-regions by 2005 . Maintaining this high abundance over an 8-year surveillance period demonstrates the difficulties related to controlling this vector, such as cleaning the accumulated organic material with appropriate waste disposal and the appropriate applied chemical control when a human case is reported.

Although the number of human cases decreased, the high $\mathrm{Lu}$. longipalpis abundance and high canine positivity in all sub-regions of the city during the 8-year study combined with the recognized eclectic feeding habits of the vector ${ }^{22,39}$ indicate that this municipality provides the appropriate conditions for an individual to acquire the disease.

Furthermore, the higher proportion of positive samples in the larger number of specimens collected in the first semester suggests that the first half of the year presents a greater risk of disease infection. Thus, the first semester should be considered to be the best time of the year to implement control strategies against $L u$. longipalpis. However, the rapid dispersion and colonization of the vector, which was assumed based on the extensive period of these collections, corresponded with the use of the recommended control activities for treating human cases (e.g., spraying insecticide around the confirmed human cases and the controversial recommendation of culling positive dogs); these factors highlight the major challenges facing policy makers who attempt to control this disease in multifaceted, urban territories and the critical need to develop new control strategies.

\section{CONFLICT OF INTEREST}

The authors declare that there is no conflict of interest.

\section{REFERENCES}

1. Maia-Elkhoury ANS, Alves WA, Sousa-Gomes ML, Sena JM, Luna EA. Visceral leishmaniasis in Brazil: trends and challenges. Cad Saude Publica 2008; 24:2941-2947. 
2. Werneck GL. Geographic spread and urbanization of visceral leishmaniasis in Brazil. Cad Saude Publica 2008; 24:2937-2940.

3. Rangel EF, Vilela ML. Lutzomyia Longipalpis (Diptera, Psycodidae, Phlebotominae) and urbanization of visceral leishmaniasis in Brazil. Cad Saude Publica 2008; 24:2948-2952.

4. Gontijo CMF, Melo MN. Leishmaniose visceral no Brasil: quadro atual desafios e perspectivas. Rev Bras Epidemiol 2004; 7:338-349.

5. Secretaria do Estado da Saúde de São Paulo. Centro de Vigilância Epidemiológica [Internet]. Vigilância Epidemiológica de Agravos: [Cited 2013 June 27]. Available at: http://www.cve.saude.sp.gov.br/htm/zoo/ lvah_lpi.htm.

6. Secretaria de Estado da Saúde de São Paulo [Internet]. Classificação epidemiológica dos municípios segundo o Programa de Vigilância e Controle da Leishmaniose Visceral Americana no Estado de São Paulo, para 2013. Boletim Epidemiológico Paulista 2011: [Cited 2013 September 9]. Available at: http://www.saude.sp.gov.br/resources/ccd/homepage/ bepa/2013/bepa_111-marco_2013.pdf.

7. Ministério da Saúde. Secretaria de Vigilância em Saúde. Departamento de vigilância epidemiológica. Manual de Vigilância e Controle da leishmaniose visceral. Brasília: Ministério da Saúde; 2006.

8. Resende MC, Camargo MCV, Vieira JRM, Nobi RCA, Porto NMN, Oliveira CDL, et al. Seasonal variation of Lutzomyia longipalpis in Belo Horizonte, State of Minas Gerais. Rev Soc Bras Med Trop 2006; 39: 51-55.

9. Silva EA, Andreotti R, Honer MR Comportamento de Lutzomyia longipalpis principal vetor da leishmaniose visceral americana em Campo Grande Estado do Mato Grosso do Sul. Rev Soc Bras Med Trop 2007; 40:420-425.

10. Jeraldo VLS, Góes MAO, Casanova C, Melo CM, Araujo ED, Brandão Filho SP, et al. Sandfly fauna in an area endemic for visceral leishmaniasis in Aracaju, State of Sergipe, Northeast Brazil. Rev Soc Bras Med Trop 2012; 45:318-322.

11. Ximenes MFFM, Silva VPM, Queiroz PVS, Rego MM, Cortez AM, Batista LMM, et al. Flebotomíneos (Diptera: Psychodidae) e leishmanioses no Rio Grande do Norte, Nordeste do Brasil-Reflexos do Ambiente antrópico. Neotropical Entomology 2007; 36:128-137.

12. Rangel O, Sampaio SMP, Ciaravolo RMC, Holcman MM. The distribution pattern of Lutzomyia longipalpis (Diptera: Psychodidae) in the peridomiciles of a sector with canine and human visceral leishmaniasis transmission in the municipality of Dracena, São Paulo, Brazil. Mem Inst Oswaldo Cruz 2012; 107:163-169.

13. Colla-Jacques FE, Casanova C, Prado AP. Study of sandfly fauna in an endemic area of American cutaneous leishmaniasis and canine visceral leishmaniasis in the municipality of Espírito Santo do Pinhal, São Paulo, Brazil. Mem Inst Oswaldo Cruz 2010; 105:208-215.

14. Instituto Brasileiro de Geografia e Estatística (IBGE). IBGE cidades. [Internet]. Brasília: IBGE [cited in 2013 July 1]. Available from http://www.ibge.gov.br/cidadesat/xtras/perfil.php?codmun=351440\& search $=\mathrm{S} \% \mathrm{C} 3 \% \mathrm{~A} 30 \% 20$ Paulo|Dracena/

15. Ministerio da Saúde (MS). [Internet]. Brasília: MS [cited 2012 December 4] Available at: http://portal.saude.gov.br/portal/arquivos/pdf/2012_11 1v_municipios_prioritarios_2009_a_2011.pdf

16. D' Andrea LAZ, Camargo-Neves VLF, Sampaio SMP. American visceral lesihmaniasis: disease control strategies in Dracena microregion in alta paulista, SP, Brazil. J Venom Anim Toxins Incl Trop Dis 2009; 15:305-324.

17. Sudia WD, Chamberlain RW. Battery operated light trap, an improvedmodel. Mosquito News 1962; 22:126-129.

18. Galati EAB. Classificação de Phlebotominae. In: Rangel EF, Lainson R, editors. Flebotomíneos do Brasil. Rio de Janeiro: FIOCRUZ; 2003. p. 23-53.

19. Coordenadoria de Assistência Técnica Integral. Escritório de desenvolvimento regional de Dracena Centro integrado de informações agrometeorológica. [Cited 2013 November 18] Available at: http://www. ciiagro.sp.gov.br/ciiagroonline/Listagens/MonClim/LMCimEDR.asp
20. Secretaria de Estado da Saúde de São Paulo. Manual de Vigilância e Controle da Leishmaniose Visceral Americana do Estado de São Paulo. [Cited 2013 November 18]. Available at: ftp://ftp.cve.saude.sp.gov.br/ doc_tec/zoo/lva06_manual.pdf.

21. Monteiro EM, França-Silva JC, Barata RA, Lara e Silva FO, Loureiro AMF, Fortes-Dias CL, et al. Phlebotominae distribuition in Janauba, an area of transmission for visceral leishmaniasis in Brazil. Mem Inst Oswaldo Cruz 2009; 104:56-61.

22. Monteiro EM, Silva JCF, Costa RT, Costa DC, Barata RA, Paula EV, et al. Leishmaniose visceral: estudo de flebotomíneos e infecção canina em Montes Claros, Minas Gerais. Rev Soc Bras Med Trop 2005; 38:147-152.

23. Barata RA, Silva JCF, Costa RT, Forte-Dias CL, Silva JC, Paula EV, et al. Phlebotomine Sandflies in Porteirinha, an area of American visceral leishmaniasis transmission in the State of Minas Gerais, Brazil. Mem Inst Oswaldo Cruz 2004; 99:481-487.

24. Oliveira DMS, Saraiva EM, Ishikawa EAY, Souza AAA, Silva EO, Silva IM. Distribuition of Phlebotomine fauna (Diptera: Psychodidae) across an urban-rural gradient in an area of endemic visceral leishmaniasis in northern Brazil. Mem Inst Oswaldo Cruz 2011; 106:1039-1044.

25. Oliveira GMG, Figueiró Filho EA, Andrade GMC, Araujo LA, Oliveira MLG, Cunha RV. Phlebotomineos (Diptera: Psychodidae: Phlebotominae) no município de Tres Lagoas, área de transmissão intensa de Leishmaniose visceral, Estado de mato Grosso do Sul, Brasil. Rev PanAmaz Saude 2010; 1:83-94.

26. Queiroz MFM, Varjão JR, Moraes SC, Salcedo GE. Analysis of sandflies (diptera:Psychodidae) em Barra do Garças, State of Mato Grosso, Brazil and the influence of environmental variables on the vector density of Lutzomyia longipalpis (Lutz \& Neiva, 1912). Rev Soc Bras Med Trop 2012; 45:313-317.

27. Souza CM, Pessanha JE, Barata RA, Monteiro EM, Costa DC, Dias ES. Study on Phlebotomine Sandfly (Dipttera: Psychodidae) Fauna in Belo Horizonte, State of Minas Gerais, Brazil. Mem Inst Oswaldo Cruz 2004; 99: 795-803.

28. Kelly DW, Dye C. Pheromones, kairomones and the aggregation dynamics of the sandfly Lutzomyia longipalpis. Anim Behav 1997; 53:721-731.

29. Quinnell RJ, Dye C. An experimental study of the peridomestic distribuition of Lutzomyia longipalpis (Diptera: Psychodidae). Bull Entom Res 1994; 84:379-392.

30. Monteiro EM, Fortes-Dias CL, França-Silva JC, Rocha MF, Barata RA, Dias ES. Association of Lutzomyia longipalpis (Diptera $>$ Psychodidae) population density with climate variables in Montes Claros, an area of American visceral leishmaniasis transmission in the state of Minas Gerais, Brazil. Mem Inst Oswaldo Cruz 2009; 104:1191-1193.

31. Amóra SSA, Bevilacqua CML, Dias EC, Feijó FMC, Oliveira PGM, Peixoto GCX, et al. Monitoring Lutzomyia longipalpis Lutz \& Neiva, 1912 in an area of intense transmission of visceral leishmaniasis in Rio Grande do Norte, Northeast Brazil. Rev Bras Parasitol Vet Jaboticabal 2010; 19:41-45.

32. Rutledge LC, Ellenwood DA. Production of phlebotomine sandflies on the open forest floor in Panama: the species complement. Environ Entomol 1975; 4:71-77.

33. Morrison AC, Ferro C, Morales A, Tesh RB, Wilson ML. Dispersal of the sandfly Lutzomyia longipalpis (Diptera: Psychodidae) at an endemic focus of visceral leishmaniasis in Colombia. J Med Entomol 1993; 30:427-435.

34. Ferro C, Pardo R, Torres M, Morrison A. Larval microhabitats of Lutzomyia longipalpis (Diptera: Psychodidae) in an endemic focus of visceral leishmaniasis in Colombia. J Med Entomol 1997; 34:719-728.

35. Laurenti MD, Rossi CN, Matta MLR, Tomokane TY, Corbett CEP, Secundino NFC, et al. Asymptomatic dogs are highly competent to transmit Leishmania (Leishmania) infantum chagasi to the natural vector Vet Parasitol 2013; 196:296-300.

36. Dantas-Torres F, Brandão Filho SP. Visceral leishmaniasis in Brazil: revisiting paradigms of epidemiology and control. Rev Inst Med Trop São Paulo 2006; 48:151-156. 
37. Góes MAO, Melo CM, Jeraldo VLS. Série temporal da leishmaniose visceral em Aracaju, estado de Sergipe, Brasil (1999 a 2008): aspectos humanos e caninos. Rev Bras Epidemiol 2012; 15:298-307.

38. Maia-Elkhoury ANS, Carmo EH, Souza-Gomes ML, Mota E. Análise dos registros de leishmaniose visceral pelo método de captura-recaptura. Rev Saude Publica 2007; 41:931-937.
39. Afonso MMS, Duarte R, Miranda JC, Caranha L, Rangel EF. Studies on the feeding habits of Lutzomyia (Lutzomyia) longipalpis (Lutz \& Neiva, 1912) (Diptera: Psychodidae: Phlebotominae) populations from endemic areas of American visceral leishmaniasis in northeastern Brazil. J Trop Med 2012; 2012:858657. 